\title{
Foreign Film as a Gateway to Cultural Studies
}

\author{
Young Imm Kang Song ${ }^{1}$ \\ ${ }^{1}$ Creative Arts in Learning Division, Graduate School of Education, Lesley University, MA, Cambridge, USA \\ Correspondence: Young Imm Kang Song, Creative Arts in Learning Division, Graduate School of Education, \\ Lesley University, Cambridge, Massachusetts 02138, USA. Tel: 1-617-349-8235. E-mail: ysong@lesley.edu
}

Received: January 21, 2013 Accepted: February 4, 2013 Available online: February 24, 2013

doi:10.11114/ijsss.v1i1.47

URL: http://dx.doi.org/10.11114/ijsss.v1i1.47

\begin{abstract}
The purpose of this article is to share an example of how a foreign film has been used as a pedagogical vehicle to understand and study the culture and society of a foreign country. It also explains how this teaching method was used to go beyond just showing the film, through a post-viewing artistic activity that used a medium reflective of the culture portrayed in the film. This article considers the following questions: How was the foreign film used as an interactive teaching tool? How did the foreign film capture and portray the country's culture and societal issues in a visual manner? What was the role of metaphor and symbolism in the film? What were the viewer's connections with the images, dialogues and sounds in the film? Did the activity of creating a visual artwork using the materials native to the culture in the film enhance the viewer's understanding of the foreign culture?
\end{abstract}

Keywords: art education, art teacher education, foreign films, cultural studies, cross-cultural issues, media literacy, Korean ink painting

\section{Introduction}

This paper discusses how foreign films can offer a lens into another culture. Specifically, it describes how a course project utilized and applied a foreign film and subsequent artistic reflections as a teaching tool. The accompanying advantages of this approach are noted as well as strategies for such applications. Processes and examples are described to show how a foreign film was used to explain thematic concepts and clarify cross-cultural issues in a course called the "Power of the Image." In this course, students were asked to create an ink painting using materials that are native to the culture portrayed in the film viewed in class. One conclusion is that images captured in foreign films can also be used to facilitate the development of new perspectives among students and enhance their understanding of various cultures.

\section{Review of Literature}

Today's visual generation has a tendency to pursue "more autonomous learning, learning as fun, and analogical learning” (Proserpio \& Gioia, 2007, p. 74). One relevant art form that has garnered much interest as an art form is film. For many years, scholars and educators of various disciplines have recognized the value of film as a teaching tool. There are many examples in research in which film was effectively utilized to enhance pedagogy (Johnston, 2011; Parker, 2009). According to Joseph Champoux (1999), using films as an educational medium can be beneficial because "films are a comfortable, familiar medium to contemporary students that can keep student interest in the theories and concepts under discussion" (p. 213). Films allow students to "see the theories and concepts in action" (Champoux, 1999, p. 213). Film can be an engaging teaching tool that appeals to many different styles of learners including those who excel at visual, auditory, and social learning. Film is also particularly good in aiding better retention because visual images are strong and their content is often emotional (Champoux, 1999).

Furthermore, although many films portray fictional circumstances, they allow the viewer to engage in a powerful experience that may be an economical alternative to a costly field trip. Films also help viewers develop analytical skills by asking students to examine the scenes, dialogues, images, sounds, and composition. By providing "both cognitive and affective experiences," films are able to "provoke good discussion, assessment of one's values, and assessment of self if the scenes have emotional content” (Champoux, 1999, p. 213). Film is engrossing in a way that few other media can match. It can also portray complexities of culture, emotion, and behavior in exceptional ways.

As such, when films are used as a medium for cross-cultural studies, they have the potential to serve as a unique 
communication tool that may enrich cross-cultural studies and help students engage in an active manner (Champoux, 1999; Summerfield, 1993). In addition, "films tell stories about people, their hopes, dreams, challenges, and fears, how they relate to others, and what behaviors are socially acceptable (and unacceptable)" (Mallinger \& Rossy, 2003). Because of this, films play a particularly important role of representing cultures and the central issues that are specific to each culture. They can quickly help unlock values, beliefs, traditions, and customs. Thus, they provide a gateway to cultural studies.

\section{Statement of Purpose}

The purpose of this article is to share an example of how a foreign film has been used as a pedagogical vehicle to understand and study the culture and society of a foreign country. It also explains how this teaching method was used to go beyond just showing the film, through a post-viewing artistic activity that used a medium reflective of the culture portrayed in the film.

This article considers the following questions:

1) How was the foreign film used as an interactive teaching tool?

2) How did the foreign film capture and portray the country's culture and societal issues in a visual manner?

3) What was the role of metaphor and symbolism in the film?

4) What were the viewer's connections with the images, dialogues and sounds in the film?

5) Did the activity of creating visual artwork using the materials native to the culture in the film enhance the viewer's understanding of the foreign culture?

\section{Process}

\subsection{Viewing the Film}

Over three years from 2008 through 2011, approximately 40 students who were enrolled in the "Power of the Image: Media Literacy" course at Lesley University, Massachusetts, U.S.A. participated in this project. This course was developed to examine "the nature and origins of images, the visual representation of minority groups in the mass media, and the use of images to create a sense of place, tell one's story, and affirm personal/cultural identity" (Lesley University, 2012). Through this course, students developed "sophistication about the power, sources and uses of imagery, and engaged in the creative process using drawing, computer-generated imagery, and video as art forms" (Lesley University, 2012). Participants in this project were all graduate students of various majors, including elementary school education, art education, middle school education, creative arts, and intercultural relations. Most participants identified as being Caucasian American, and three, two, and one participant identified as being Latin American, Asian American, and African American, respectively. Most participants did not have any prior experiences with Asian ink paintings.

These students viewed a variety of films. One of the films shown was a Korean film entitled Spring, Summer, Fall, Winter, ... and Spring. This film was written, directed, and edited in 2003 by director Kim Ki-duk. It received much acclaim and won five international film festival awards. It has minimal dialogue and is set in an isolated Korean Buddhist temple. The film is divided into five segments and each season represents a stage of the main character's life as a metaphor for human life in general. According to the director, through the film he intended to "portray the joy, anger, sorrow, and pleasure of our lives through the four seasons and through the life of a monk" (Sony Pictures Classics, 2004).

\subsection{Preparing to Create a Korean Ink Painting}

After viewing the film, students participated in a project of creating a Korean ink painting with white rice paper, black ink, and a traditional painting brush. Before beginning the painting itself, the students first learned basic ink painting techniques. These included how to hold a brush, how to make ink, how to use an ink tray, and how to use the brush. Learning these techniques communicated to the students several philosophies of Korean traditions, specifically in terms of creating ink paintings, such as the unification of humans and nature, and the unification of subjectivity and objectivity. The images depicted in many ink paintings are those of nature. In painting them, the artist connects deeply with the subject of his work. Some elements of the paintings are more literal while others have figurative embellishments that show the individual's interpretation or understanding of the subject matter.

To internalize the philosophy of ink painting, the students meditated briefly before beginning the activity. While the students closed their eyes, the instructor posed a variety of questions in a guided meditation. The questions included asking the students to think about the images that they remembered, with the intention of encouraging a self-reflective process. 


\subsection{Creating a Korean Ink Painting}

After the meditation, the instructor asked the students to create a painting that reflected their understanding of the film. This was not necessarily meant to be a representation or a direct portrayal of the film. Instead, it was meant to reflect what they personally took away from the film. Students used the techniques they had recently learned as well as the knowledge of ink paintings from the film to create their own ink painting reflections of the film. Examples of the students' ink paintings are described in the discussion section of this paper.

This activity was developed as a way to enrich the learning experience by encouraging a form of critical thinking and active engagement with the film. According to Proserpio and Gioia (2007), effective learning requires "active involvement by students in the learning process" (p. 74). Active engagement in the creative process helps students visualize and understand better what is being communicated. Students were able to utilize the artistic process to creatively reflect on the film and integrate their thoughts into a visual medium.

In this particular case, students were asked to create a Korean ink painting because this type of painting played an important role in the film. More specifically, the ink painting served as a metaphor for the process of growth, development, maturation, and inner reflection of the central protagonist. The creation of the painting includes several stages that are analogous to those of the main character. The painting begins with a blank piece of paper and grows outward and develops as the artist adds details, refines the images, imbues meaning, and enriches the design to create a robust final product.

\subsection{Creating Watercolor Images}

Afterwards, students also created images using watercolors to answer the same questions as before. This activity was meant to help students see how the process of creating a watercolor image feels different from the process of creating a Korean ink painting, if at all. It was also meant to help students see how the two artworks differed. For this activity, the instructor selected watercolors because it is a medium that is more familiar to the students and contrasts with Korean paintings, which are entirely black and white.

\subsection{Writing a Reflection Paper}

To conclude, students were asked to reflect upon each step of the process (viewing the film, learning about how to create an ink painting, meditating, creating an ink painting, and creating a watercolor image) in a written assignment. This written piece was meant to help each student reflect upon and bring together what the process meant for him or her. Using their own paintings as a guide, the students wrote a reflection about their experiences. This was intended to be a complex transaction, moving from viewing a film to putting black ink on white paper, and finally to writing words. Ideally by engaging with the material in several ways-through viewing a film, planning and creating two visual artworks, and writing an analytic reflection, students would gain a understanding of the culture presented in the film as well as their own responses to it.

\subsection{Holding a Class Discussion}

Immediately after viewing the film, students were asked to proceed directly to their own reflections rather than jumping into a class discussion. Of this, student Jessica Perry (2008) said, "The brushwork exercise at the end of viewing the film was the most necessary quiet activity, thank you! It wasn't meant at that time for a class discussion but a time to sit with yourself and create!” The class discussion was purposefully held in the subsequent class. The following section details the reflections and lessons that emerged from this class discussion.

\section{Discussion}

The current generation is more receptive to new forms of information, having been raised on new forms of media such as television, film, and computers. As the entertainment, education, and advertising industries increasingly utilize visual imagery, young people have gained significant exposure to film in both formal and informal contexts. Students in this class were generally excited and enthusiastic about utilizing film as a tool to learn about a foreign culture. In their reflection papers and discussions, they conveyed that films are particularly good for this role because of their ability to convey a rich context. With the passive experience gained through viewing the film and the active experience gained through the post-viewing activities, the students were very positive about what they described as a deeply engaging activity to study another culture.

In what follows, this section draws upon the students' observations and discussion to assess how the foreign film was used as an interactive teaching method.

\subsection{How did the Foreign Film Capture and Portray the Country's Culture and Societal Issues in a Visual Manner?}

According to Mallinger and Rossy (2003), "film [can] be particularly useful in teaching not only the broad 
concepts of culture but its complexities as well, especially the ambiguities and paradoxes that characterize the subtleties of interactions among individuals from different cultures” (p. 613). This is because viewers do not stop at simply observing what is projected onto the screen, but instead go a step further and emotionally respond to the unique elements and features of the film. Many, if not most, films and filmmakers attribute great significance to this emotional response in creating films and judging their success (Champoux, 1999; Allbritton and Gerrig, 1991; Gerrig and Prentice, 1996). Film is able to not only portray dialogue and imagery, but mood, tone, inference, allusion, and norms.

One of the students, Margaret Waugh (2011), wrote: "One of the differences between East and West that was featured in this film is medicine and how we help to cure sickness. When the Young Woman is sick, her mother takes her to the Old Monk to help her 'find peace in her soul.' While she is there, she is told to rest and pray. The Old Monk and Boy Monk prepare medicine for her that is made of leaves from the forest. In Western culture, when someone is sick the first thing we do is go to the medicine cabinet to take a pill or two that will make the symptoms go away. In Western culture, when we get sick we do not think about our soul in relationship to the illness, instead we take an unnatural substance that says it will cure the symptoms we are feeling."

Another student, Liza Gladstein (2009), said: "Eastern culture connects with nature. This is evident with the multiple references to water, air, land, and fire. In Eastern aesthetics, people try to blend in with their environment." In a short reflection, Skye Murrill (2011) wrote: "I feel that the difference between Western aesthetics and Eastern aesthetics is the level of focus, respect, and value placed throughout life." Also, Richard Roche (2008) said: "Western aesthetics are seemingly more concerned with definitive shapes and the making of them. The East seems more resigned to going with the flow and acceptance."

In their brief reflections, students compared eastern aesthetics to western aesthetics in various ways and noted differences in cultural values, priorities, and beliefs. But as one student, Diem Dangers (2008) noted, it is important not to fall into the trap of dualism. This is because reality is much more complex, intertwined, difficult to juxtapose, and composed of several layers in which both eastern aesthetics and western aesthetics coexist and are distinct at the same time. Students generally reported that this was an interesting exercise in which they were encouraged to articulate their thoughts on eastern and western aesthetics, and identify the similarities and differences.

\subsection{Examples of Students' Artworks}

The following is a sample of comments from student discussions that express their connection with the artistic technique and the culture. One of the students, Nancy Jo Cardillo (2008), expressed "The act of painting was an extension of the meditative flow of the film - although in my newness to the art form, I did not quite achieve that state of being. I carried into my brush painting the sense of rhythm and repetition that I found soothing, reassuring, and conscious-making."

Another student, Jessica Perry (2008), described her artwork (see figure 1), "As I was working with the water I trailed down to create the waterfall and began to realize it started to look tree-like. This unintended imagery then led me to create roots in the ground and then back up to create a sky over the boat. In the end, I found it very symbolic that all four elements were present. All these elements were also present and symbolic of phases of life in the film. A true quality Asian brushwork makes all the visual fragments create a whole in the end, a feeling of oneness.”

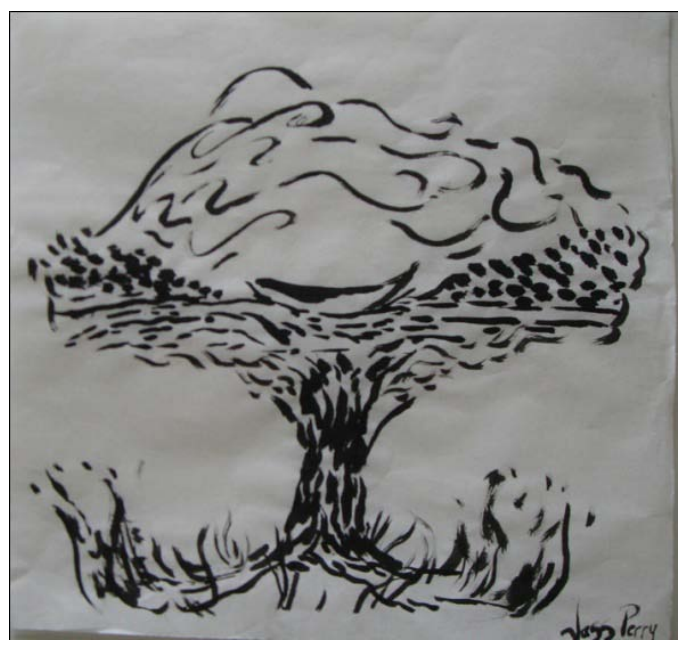

Figure 1. Artwork by Jessica Perry, 2008 
Another student, Skye Murrill (2011), said about her artwork (see figure 2), "I feel that the images that stood out to me were the ones that I connected with on a personal level. My painting was composed of three major images from the film. First, I made a connection with the image of the cat and his blackened tail. This image spoke to me as a symbol of loyalty and presented a connection to the animal world. I also connected strongly with the image of the hermitage or shikibu in which the characters lived. This was a safe haven for all to come and be at peace. Finally, my painting was composed of the landscape itself, of course making a connection with nature."

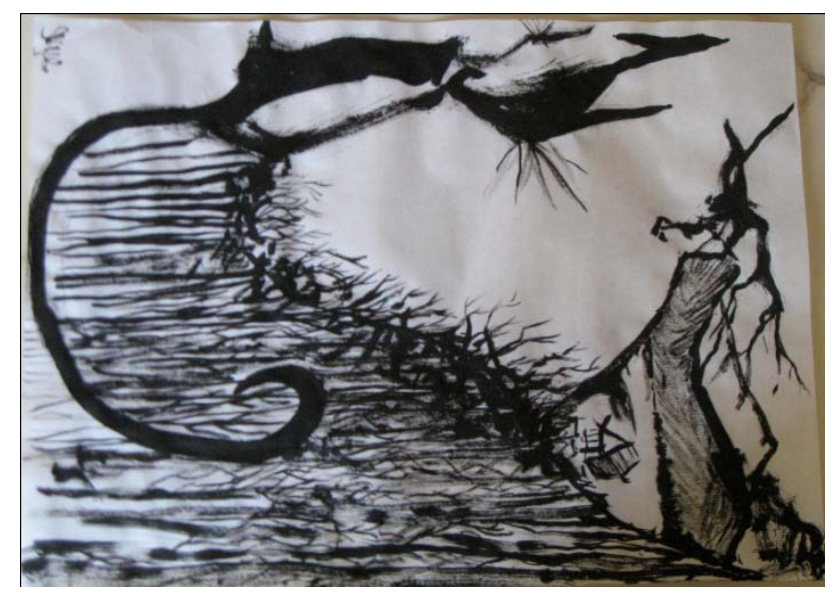

Figure 2. Artwork by Skye Murrill, 2011

Student Lisa Ginivisian (2008) explained, "Without hesitation but with intention, I painted a tree as my reflection painting. The tree appeared when the characters in the film entered and exited the doors of the monastery. The tree was the first image to me that identified what season the story was taking place. The tree also symbolized growth, health and change by its colors and various stages. The tree was metaphoric for the sustenance and longevity of life no matter what happens to us" (see figure 3).

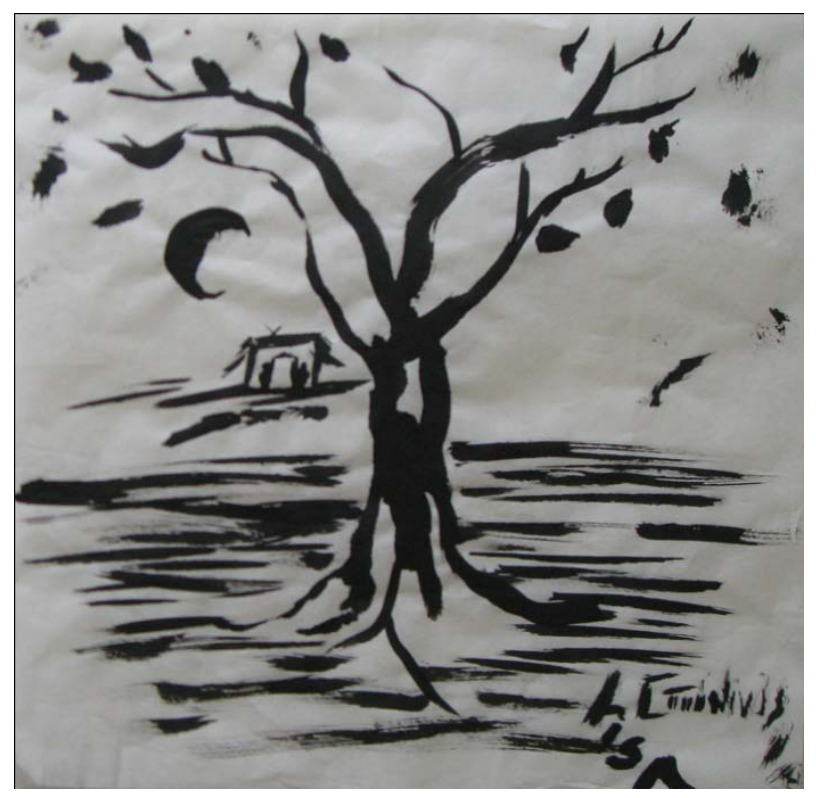

Figure 3. Artwork by Lisa Ginivisian, 2008

Student Amy Grady (2008) discussed, "Some images really stuck with me. The passing of the seasons was portrayed through the repeated opening of the doors onto the lake.... It was very interesting how the monk was surrounded only by nature, but was able to experience the happiness, rage, sadness and bliss of life, as depicted through the four seasons" (see figure 4). 


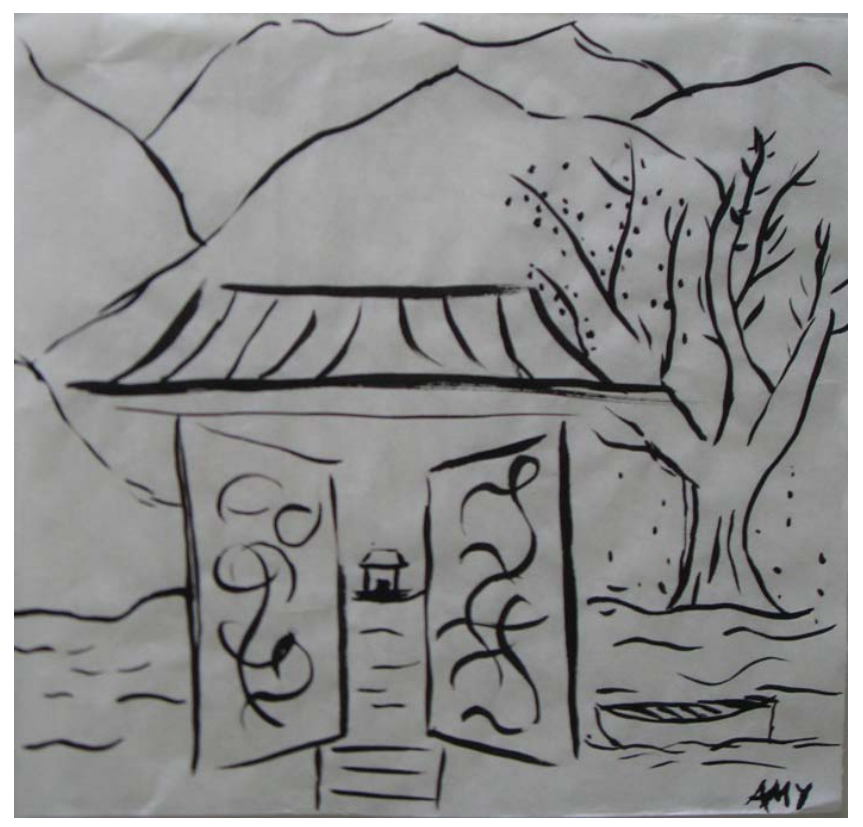

Figure 4. Artwork by Amy Grady (2008)

Student Christina Delaney (2008) said about her artwork (see figure 5), "I represented the great mountains and delicate yet strong trees in my brushwork, which was inspired by the landscape shown throughout the film.”

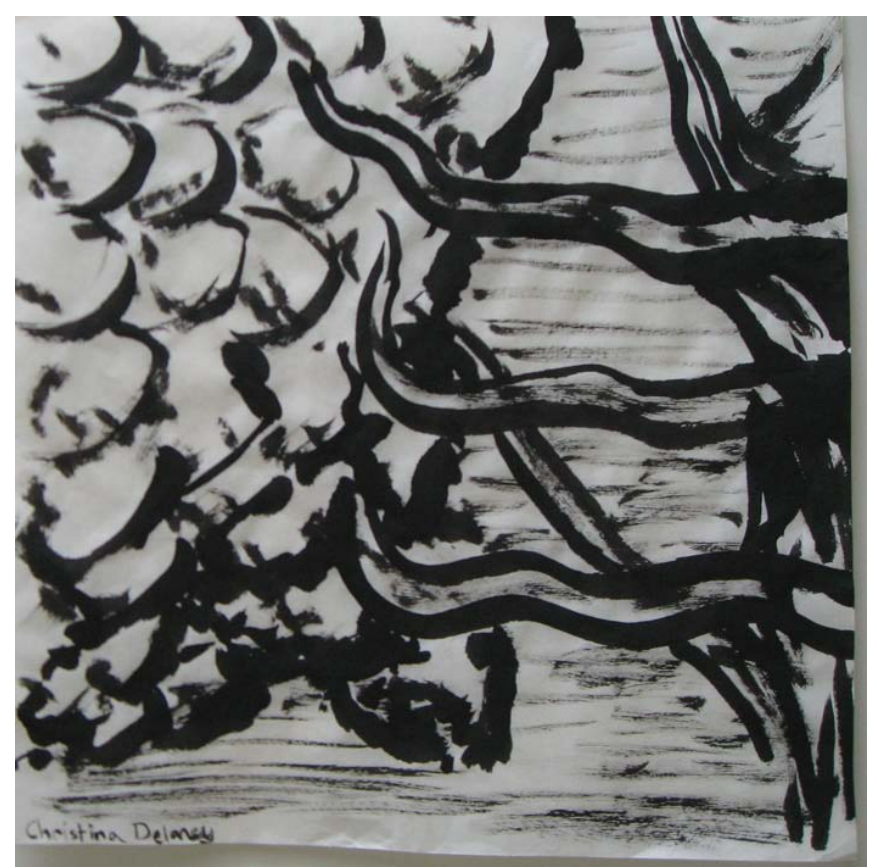

Figure 5. Artwork by Christina Delaney, 2008

Student Richard Roche (2008) explained his artwork (see figure 6). "The gate at the front-left with the fighters on them represent gates in and out of the world, where to enter the temple of tranquility is to gain strength.” 


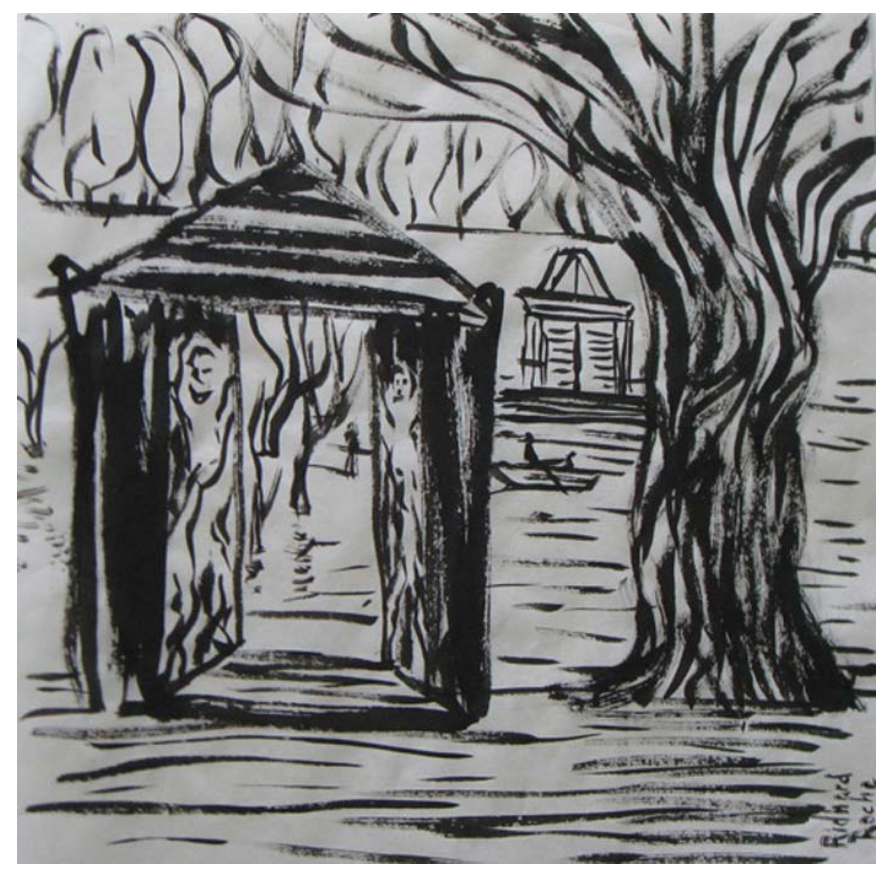

Figure 6. Artwork by Richard Roche, 2008

Student Jordan Lund (2008) discussed her artwork (see figure 7). "I began my painting using a curved line to show the fluidity and movement of the film, which represented the change of seasons."

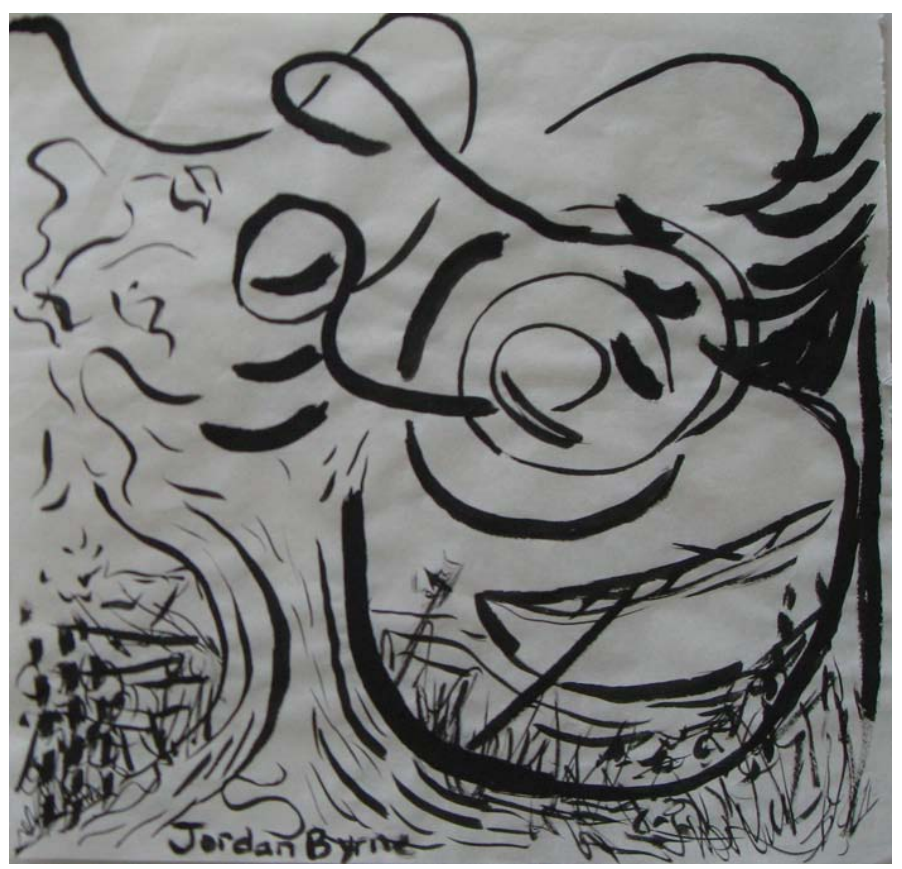

Figure 7. Artwork by Jordan Lund, 2008

Student Lawrence Szalay (2009) said about his artwork (see figure 8), "I painted the doors by the shore, the large three-hundred-year-old tree, the fish that was bound to the stone, and the monk in his burning boat. I tried to paint aspects of the movie that both intrigued me, puzzled me, and that I thought I understood on some level.” 


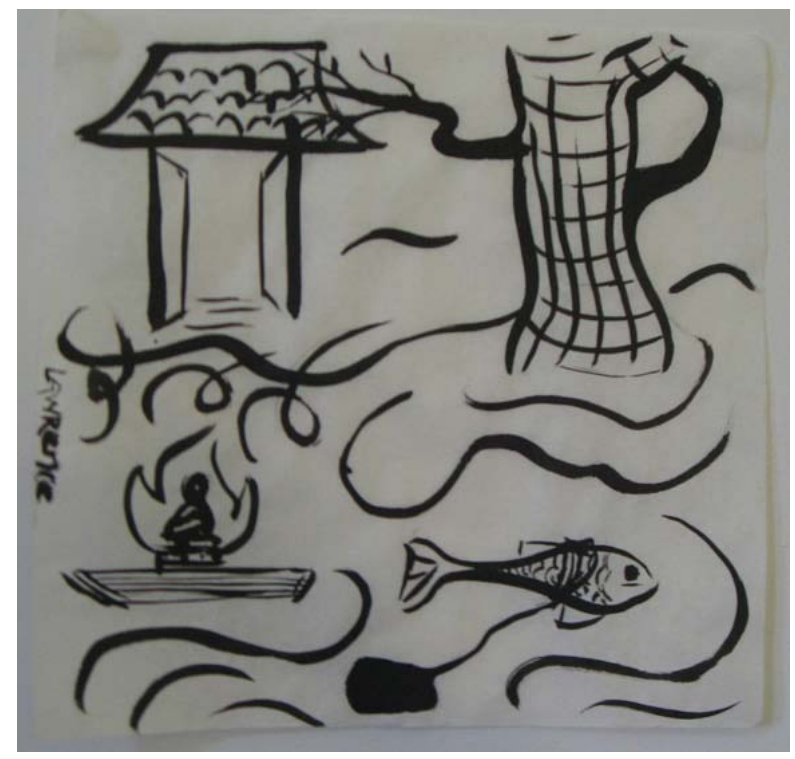

Figure 8. Artwork by Lawrence Szalay, 2009

Despite the fact that they were using art materials that were unfamiliar to them, students demonstrated an ability to easily express themselves in a variety of ways. According to the reflections of many students, key elements of the film that are important in Korean culture resonated with them and were depicted in their paintings. These included elements of nature, the idea of continual growth and rebirth, meditation, and a feeling of "oneness." By identifying key metaphors and symbols and incorporating these into their own works, students were able to explore another culture, identify personal connections, and think critically about its meaning.

\subsection{The Role of Metaphors and Symbols within Films}

According to many scholars and artists, metaphors are powerful tools in literary forms, such as prose and poetry. Some also argue that metaphors play an important role when using films as a teaching tool (Cooper, 1986; Hawkes, 1972; Mooij, 1976). This is because metaphors within films "clarify complex thoughts, bring vividness to abstractions, magnify a thought for dramatic effect, and [allow the viewer to] gain insight. A vital function of metaphor is the expression of imagination and stimulating imaginative images in a reader or listener" (Hawkes, 1972, p. 34).

Students were able to identify several metaphors in the film Spring, Summer, Fall, Winter,...and Spring. Most interpreted the metaphors and symbols in a way that helped improve their understanding of the foreign culture. Some students noted that the film portrayed and simulated the "human experience" and "real world dilemmas" through a variety of symbols and metaphors. One of the students, Skye Murrill (2011), explained: "The strongest metaphor that I received from the film was the adult monk's extensive struggle up the mountain. I felt this was a very straightforward metaphor for life. Life in general is a struggle to get to a place where you feel at peace. There will always be something holding you back, just as the stone was holding the adult monk back, making his journey more difficult. The adult monk held on to his religious statue, lost it, but went back to get it, and continued forward. Everyone holds on to something that encourages them to keep going, even if they do lose it, most will go back to grab it. I thought about this metaphor just this weekend and reminded myself to keep going, and I would get to where I needed to be eventually.”

Another student, Margaret Waugh (2011), described how the film seemed to convey metaphors for abstract ideas and concepts. She explained: "One of the metaphors that I saw in this film was the rock and how it symbolizes the decisions that we make, both good and bad, and how they stick with us throughout our lives. In the beginning we watch the Boy Monk as he struggles walking with the rock. The rock tied to his back is new, and he is not used to its weight or the heaviness of the rock. As he grows into an Adult Monk his struggle with the rock is easier, but there are times when the weight of the rock is too much to bear and in turn he loses his balance. Instead of giving up, he collects himself and regains [his] footing and keeps going." Champoux (1999) writes about a similar idea, in which he tells that film directors often use images as metaphors for key ideas that deserve emphasis, both intentionally and unintentionally (p. 210).

Also, several students discussed water as a metaphor in the film. Jennifer Sutherland (2011) described, "The water 
of the lake itself is a Buddhist symbol of purity. It is fitting that the Young Monk would return to this place to cleanse his soul after committing his crime. In one scene we see the old monk writing mantras with water on a stone. The first characters disappear by the time he has finished, and he must start again with a blank stone. This type of meditation is a metaphor for the transience of life, a central theme in the film.” Here, the metaphor served as an "expression of imagination" that brought out the students' creative ideas (Hawkes, 1972, p. 34). Some students also discussed the doors and gates as symbols. Liza Gladstein (2009) said: "I enjoyed the use of the gate as a transition between seasons and time; it marked the entry into a new place in the story. In the context of the film, doors held deeper meanings: passageways through time and spiritual realms. The doorways at the entrance to the lake marked the exit from 'the world of man' and into the higher spiritual place of the monastery, and within the monastery, they marked the transition between sleep quarters and area of the shrine, within the one room structure." Another student, Nancy Jo Cardillo (2008), described: "The doorways offered openings from one world, realm or state of being to another. More than just a transition from one season to the next, in the house, they marked the transition from a sleeping state to an awake state, from the resting place to the prayer or commonplace.”

Amy Grady (2008) explained: "I noticed the correlation of the seasons to the journey of the human spirit: spring = innocence, summer $=$ love, fall $=$ evil, winter $=$ enlightenment, spring $=$ rebirth. It makes this story seem as though it is universal and could be carried across cultures throughout the world." Her interpretation of the metaphors suggests that novel and creative meanings for symbols are often assigned based on cultural contexts (Young, 2000).

Overall, students enjoyed the experience of identifying metaphors and symbols from the film, and it was evident that the activity helped them fully engage in the viewing of the film. As a teaching exercise, this was a useful activity. As Champoux (1999) writes, "[a] metaphor does not distort the facts described; it offers a new way of experiencing those facts. Metaphors often leave lasting impressions that a person easily recalls” (p. 210).

\subsection{What Were the Viewer's Connections with the Images, Dialogue, and Sounds in the Film?}

The students reflected that the landscape of the film was particularly memorable because there was very little dialogue. A few themes really stood out, including the notions of innocence, enlightenment, and rebirth; the importance of forgiveness; and the value of meditation. In addition to the visual images, the sounds captured in the film were very meaningful in understanding the visual images, again because the dialogue was minimal. Several students reflected on this very point:

"The image from this film that stuck with me, and influenced my painting, was the image of the waterfall. With the change of each season, the sound of the flow of the water going down the waterfall also changed. The first time we hear the waterfall is in the spring and it is strong and loud, but never overpowers the sounds or actions of the Boy Monk. In the summer, the sounds of the waterfall become louder and help to hide the Boy Monk's romantic relationship. In the fall, the sound of the water hitting the rocks is harsh and becomes a symbol of the Young Adult Monk's crime. In the winter the waterfall is still there, but sounds tranquil and quiet for most of it is frozen. In spring again, the waterfall becomes unfrozen and full of life again. No matter the season the waterfall, like life, keeps going” (Margaret Waugh, 2011).

"I loved the lack of dialogue. I believe that this helped to enhance the metaphors, foreshadowing, and parallels that could be drawn about the movie" (Lawrence Szalay, 2009). Another student concurred with this view, saying "It is in this minimalism that the film finds much of its potency. There was a certain stillness to the overall composition that was enhanced by the limited dialogue" (Liza Gladstein, 2009). Jessica Perry (2008) described the film's focus on imagery as "rich with visual language."

These students explained how the sights, sounds, and words in the film helped further their understanding about the messages and values being depicted by the story. Despite limited dialogue, the film conveyed strong meaning that students were able to identify and relate to through images and metaphors.

5.5 Does the Activity of Creating a Visual Artwork Using the Materials Native to the Culture Portrayed in the Film Enhance the Viewer's Understanding of the Foreign Culture?

The students highlighted the power of the material and the power of the image in their discussions about the Korean ink painting activity and the watercolor activity. When creating the Korean ink painting, students noted that they felt like they were directly experiencing Korean culture through the process of using the ink stone, black ink, and a traditional Korean brush to draw on rice paper. This was more so than when they created a watercolor image. Students said that they felt more closely connected to the characters in the film, and felt a better understanding of the culture itself when creating the Korean ink painting. When creating the watercolor, they expressed that it was a much faster process that required much less thought because of the familiarity. 


\section{Conclusion}

In this case, using a film and a subsequent visual art project as a pedagogical medium to understand and study the culture of a foreign country was beneficial. It helped students engage with the course content and themes with enthusiasm and curiosity. Through these activities, it was evident that some students interpreted the metaphors and meanings of the film through their own perspectives that were shaped by their own experiences. This process of engaging in a personal and individual re-interpretation of the meanings embedded in the foreign film is important to understanding another culture and to ensuring a deep level of learning and engagement. Through the painting activity, this interpretation is made active rather than simply passive. Students do not simply view the film but are encouraged to internalize and express their reactions to the film and the embedded culture by portraying the symbols, metaphors, and motifs in an image. As such, using foreign films as part of cultural studies, having an interactive discussion, and creating visual artworks that utilize the materials native to the traditions captured in the films may have an important pedagogical value.

\section{Acknowledgements}

The author thanks the students of the "Power of the Image" course for their enthusiasm, passion, and dedication to the projects and class discussions. The author also expresses her gratitude to her colleagues Professor Sam Smiley and Professor Prilly Sanville for their support.

\section{References}

Albritton, D. W., \& Gerrig, R. J. (1991). Participatory responses in prose understanding. Journal of Memory and Language, 30, 603-626. http://dx.doi.org/10.1016/0749-596X(91)90028-I

Champoux, J. E. (1999). Film as a teaching resource. Journal of Management Inquiry, 8(2), 206-217. http://dx.doi.org/10.1177/105649269982016

Cooper, D. E. (1986). Metaphor. Oxford, UK: Basil Blackwell.

Dalton, M. M. (2004). The Hollywood curriculum: Teachers in the movies. New York: Peter Lang.

Eisner, E. W. (1991). The enlightened eye: Qualitative inquiry and the enhancement of educational practice. New York: Macmillan.

Gerrig, R, J., \& Prentice, D. A. (1996). Notes on audience response. In D. Bordwell \& N. Carroll. (Eds.), Post-theory: Reconstructing film studies. Madison: University of Wisconsin Press.

Hawkes, T. (1972). Metaphor. London: Methuen.

Johnston, C. (2001). Movies are the key to lively lectures. Times Higher Education Supplement, 1945, 13.

Lesley University. (2012). Course description. Retrieved from http://www.lesley.edu/GSOE/

Mallinger, M., \& Rossy, G. (2003). Film as a lens for teaching culture: Balancing concepts, ambiguity, and paradox. Journal of Management Education, 27(5), 608-624. http://dx.doi.org/10.1177/1052562903252642

Mooij, J. J. A. (1976). A study of metaphor, on the nature of metaphorical expressions, with special references to their reference. Amsterdam: North Holland.

Parker, R. (2009). Watch this clip: Using film as an augmentation to lecture and class discussion. Academy of Educational Leadership Journal, 13(4), 129-134.

Proserpio, L., \& Gioia, D. A. (2007). Teaching the virtual generation. Academy of Management Learning and Education, 6, 69-80. http://dx.doi.org/10.5465/AMLE.2007.24401703

Sony Pictures Classics. (2004). Director's statement. retrieved January 10, 2011 from http:/www.sonyclassics.com

Summerfield, E. (1993). Crossing cultures through film. Yarmouth, ME: Intercultural Press.

Young, S. D. (2000). Movies as equipment for living: A developmental analysis of the importance of film in everyday life. Critical Studies in Media Communication, 17(4), 447-468. http://dx.doi.org/10.1080/15295030009388413

\section{(cc) Br}

This work is licensed under a Creative Commons Attribution 3.0 License. 